\title{
The steroid receptor antagonists RU40555 and RU486 activate glucocorticoid receptor translocation and are not excreted by the steroid hormones transporter in $\mathbf{L 9 2 9}$ cells
}

\author{
C M Pariante', B D Pearce, T L Pisell, C Su and A H Miller \\ Department of Psychiatry and Behavioral Sciences, Emory University School of Medicine, Atlanta, Georgia, USA \\ ${ }^{1}$ Section of Clinical Neuropharmacology, Institute of Psychiatry, King's College London, London, UK \\ (Requests for offprints should be addressed to C M Pariante, Section of Clinical Neuropharmacology, Institute of Psychiatry, King's College, 1 Windsor Walk, \\ Denmark Hill, London SE5 8AF, UK; Email: spjucmp@iop.kcl.ac.uk)
}

\begin{abstract}
RU40555 is a recently available glucocorticoid receptor (GR) antagonist that differs from RU486 by a methyl radical. We have used the mouse fibroblast cell line L929 to study the in vitro effects of RU40555 on GR translocation and function and on the membrane steroid hormones transporter. The results showed that: 1) RU40555 competed for the binding of labelled dexamethasone (Dex) with a $K_{\mathrm{i}}$ of $2 \cdot 4 \mathrm{nM}$; 2) both RU40555 and RU486 were equally potent inhibitors of Dexinduced GR-mediated gene transcription; 3) maximum GR translocation induced by micromolar concentrations of Dex and the GR antagonists was 30-55\% loss in the cytoplasmic GR and 40-90\% increase in the nuclear GR (assessed by GR immunostaining in cytoplasm and nucleus and western blots of immunoprecipitated GR protein in cytosolic and nuclear fractions) and was similar for the two antagonists; 4) at nanomolar concentrations,
\end{abstract}

RU40555 and RU486 induced more GR translocation than Dex (assessed by $\left[{ }^{3} \mathrm{H}\right]$ Dex binding and western blot of immunoreactive GR in the same cytosolic homogenates); 5) blocking the steroids membrane transporter with verapamil $(100 \mu \mathrm{M})$ in the presence of Dex $(10 \mathrm{nM})$ increased GR translocation to levels similar to those induced by RU40555 $(10 \mathrm{nM})$ and RU486 (10 nM) alone; 6) verapamil did not affect GR translocation in the presence of RU40555 or RU486. These data demonstrate similar quantitative effects on GR translocation by RU486 and the new GR antagonist, RU40555. Moreover, RU40555, like RU486, is an effective GR antagonist. Finally, there is no evidence that the intracellular concentrations of RU40555 or RU486 are regulated by the steroids membrane transporter in L929 cells.

Journal of Endocrinology (2001) 169, 309-320

\section{Introduction}

The glucocorticoid receptor (GR) is a ligand-induced transcription factor that belongs to the steroid/thyroid receptor superfamily (Ing \& O'Malley 1995). The unactivated receptor is associated non-covalently with heat shock protein (hsp) 90, hsp70 and hsp56 in a large heteromeric complex that resides primarily in the cytoplasm (Pratt 1993). The cytoplasmic receptor, when bound by steroid, undergoes a conformational change ('activation'), dissociates from the hsp complex and exposes the so-called 'nuclear localisation signal' (NLS) region that allows translocation from the cytoplasm to the nucleus (Picard \& Yamamoto 1987). In the nucleus, the activated receptor influences gene transcription either by binding to glucocorticoid response elements (GREs) or by interacting with other transcription factors (Ing \& O'Malley 1995). We and others have shown that treatment with GR agonists increases nuclear staining in immunocytochemistry assays using antibodies against GR (Rupprecht et al. 1993, Czar et al. 1995, Jewell et al. 1995, Yang \& DeFranco 1996, Pariante et al. 1997, 1999), and shifts the GR signal from the cytosolic to the nuclear fraction after hypotonic cell rupture or homogenisation (Beck et al. 1993, Sanchez et al. 1994, Sackey et al. 1996, Pariante et al. 1997). Moreover, a recent study by Htun et al. (1996) has confirmed the hormone-dependent translocation of the cytoplasmic GR into the nucleus, using time-lapse video microscopy of live cells.

Interestingly, the GR antagonist, RU486, has been shown to mimic some of the events related to GR activation, including increased nuclear GR staining in immunocytochemical studies (Qi et al. 1990, Rupprecht et al. 1993, Jewell et al. 1995, Htun et al. 1996, Sackey et al. 1996) and binding to DNA (Schmidt 1986, Beck et al. 1993). Progesterone, another GR antagonist, also has been shown to induce nuclear localisation of the immunostained GR (Rupprecht et al. 1993). 
RU40555 is a new GR antagonist (recently introduced by Roussel Uclaf) that differs from RU486 by a methyl radical. Similarly to RU486, RU40555 has affinity for both the GR and the progesterone receptor. It has been used as a GR antagonist in animal research and has been demonstrated to have no affinity for the mineralocorticoid receptor (Kim et al. 1998, Spencer et al. 1998). However, no study has investigated the effects of RU40555 on GR translocation in vitro. In the present study, we used L929 mouse fibroblast cells to compare the effects of in vitro treatment with the GR agonist, dexamethasone (Dex), and the GR antagonists, RU40555 and RU486, on a panel of quantitative assays investigating GR subcellular localisation and function (Pariante et al. 1997, 1999).

Interestingly, some GR ligands such as cortisol and Dex - but not corticosterone and progesterone - are actively excreted from cells by membrane transporters belonging to the ATP-binding cassette family of transporters (Ueda et al. 1992, Kralli \& Yamamoto 1996, Medh et al. 1998). One of these transporters, the multiple drug resistance (MDR) p-glycoprotein, has been extensively described to regulate intracellular concentrations of steroids, to secrete naturally occurring metabolites and toxic substances directly into the urinary or gastrointestinal tracts, and to confer treatment resistance to tumour cells (Ueda et al. 1992, Krishna \& Mayer 2000). However, other transporters with similar substrate profiles have been reported (Krishna \& Mayer 2000). For example, the L929 mouse fibroblast cell line also expresses a membrane steroid transporter, which seems to be similar, but not identical, to MDR p-glycoprotein (Kralli \& Yamamoto 1998, Marsaud et al. 1998). Because it is known that RU486 is not transported by the MDR p-glycoprotein (Gruol \& Bourgeois 1994), we have examined whether RU486 and RU40555 are transported by the L929 cells membrane steroid transporter.

We evaluated: 1) GR-mediated gene expression in cells stably transfected with the mouse mammary tumour virus-chloramphenicol acetyltransferase (MMTV-CAT) reporter gene; 2) quantitative analysis of fluorescence after GR immunostaining; 3) quantitative western immunoblotting of immunoprecipitated GR protein in cytosolic and nuclear fractions; and 4) $\left[{ }^{3} \mathrm{H}\right]$ Dex receptor binding and western blot of GR protein in the same cytosolic homogenates. We found that, in L929 cells, RU40555 and RU486: 1) equally block Dex-induced GR-mediated gene transcription; 2) induce a similar amount of maximum GR translocation; and 3) are not excreted by the membrane steroid transporter.

\section{Materials and Methods}

\section{Materials}

Unlabelled Dex was obtained from Sigma (Poole, Dorset, UK). $\left[6,7-{ }^{3} \mathrm{H}(N)\right]-$ Dexamethasone $(43 \cdot 2 \mathrm{Ci} / \mathrm{mmol})$ was obtained from New England Nuclear (Boston, MA, USA). Human fibronectin was obtained from Becton Dickinson Labware (Franklin Lakes, NJ, USA). The LMCAT cell line was generously provided by ER Sanchez (Department of Pharmacology, Medical College of Ohio, Toledo, OH, USA).

\section{Cell culture conditions and drug treatments}

Mouse fibroblast cells (L929) and the stably transfected CAT reporter cell line LMCAT (derived from L929 (Sanchez et al. 1994)) were maintained in $175 \mathrm{~cm}^{2}$ flasks (Becton Dickinson Labware) at $37{ }^{\circ} \mathrm{C}$ with a $5 \% \mathrm{CO}_{2}$ and 95\% air atmosphere. The culture medium for L929 cells was DMEM with $10 \%(\mathrm{v} / \mathrm{v})$ heat-inactivated $\left(56^{\circ} \mathrm{C}\right.$, $30 \mathrm{~min}$ ) calf serum, $50 \mathrm{U} / \mathrm{ml}$ penicillin, and $50 \mu \mathrm{g} / \mathrm{ml}$ streptomycin. For immunostaining, cells were grown in DMEM with charcoal-extracted (1\% charcoal activated, $0 \cdot 1 \%$ dextran) calf bovine serum. For LMCAT cells, culture medium was DMEM with 10\% (v/v) charcoalextracted, heat-inactivated $\left(56{ }^{\circ} \mathrm{C}, 30 \mathrm{~min}\right)$ newborn calf serum and $0.2 \mathrm{mg} / \mathrm{ml} \mathrm{G} 418$ (Geneticin) antibiotic.

For the CAT assay, LMCAT cells were subcultured in fibronectin-coated 6-well plates and grown for $12 \mathrm{~h}$ (final confluency 95\%) before drug treatment. For immunoprecipitation/western blotting, L929 cells were subcultured in fibronectin-coated $175 \mathrm{~cm}^{2}$ flasks for 48-72 h (final confluency 95\%) before drug treatment. For immunostaining, cells were transferred into fibronectin-coated chamber slides (Nunc, Napperville, IL, USA) for $12 \mathrm{~h}$ to obtain a final confluency of approximately $70 \%$, and then drug treated.

Treatment of both L929 cells and LMCATs for all assays consisted of incubation with fresh medium containing vehicle (ethanol, final concentration $<0.04 \%$ ), or final concentrations of Dex $(1 \mathrm{nM}, 10 \mathrm{nM}$ or $10 \mu \mathrm{M})$, RU40555 (1 nM, $10 \mathrm{nM}$ or $40 \mu \mathrm{M})$ or RU486 (1 nM, $10 \mathrm{nM}$ or $40 \mu \mathrm{M})$ for $1.5 \mathrm{~h}$. In some experiments, cells were treated with verapamil $(100 \mu \mathrm{M})$ for $18 \mathrm{~h}$, followed by verapamil and the GR ligands for $1.5 \mathrm{~h}$. The GRmediated gene transcription study included a series of experiments in which LMCAT cells were incubated with RU40555 or RU486 alone for $24 \mathrm{~h}$.

\section{CAT reporter cell line and CAT assay}

The LMCAT cell line (derived from L929 cells) is stably transfected with the MMTV-CAT reporter plasmid. Expression of CAT activity by these cells is under hormonal control by virtue of several GREs residing within the MMTV promoter, which lies upstream of the CAT reporter gene (Sanchez et al. 1994). We have reported that the expression of CAT activity is dependent on both the concentrations of the steroid hormones and the duration of the incubation. Dex $(10 \mu \mathrm{M})$ for $24 \mathrm{~h}$ gives approximately 180 -fold induction 
compared with vehicle-treated cells, Dex $(10 \mu \mathrm{M})$ for $1.5 \mathrm{~h}$ gives approximately a 20 -fold induction, and Dex $(10 \mathrm{nM})$ for $1.5 \mathrm{~h}$ gives approximately a twofold induction (Pariante et al. 1997). For each incubation time, Dex $(10 \mu \mathrm{M})$ gives the maximum induction of CAT expression. We decided to treat cells for $1.5 \mathrm{~h}$, to minimise the possibility of steroid-induced changes in GR expression, which could also affect the CAT activity (Pariante et al. 1999).

Measurement of CAT enzyme activity was performed using a liquid scintillation counting detection system (Promega, Madison, WI, USA) according to the manufacturer's instructions. Briefly, cell extracts were obtained using a Tris buffer $(0 \cdot 25 \mathrm{M}$ Tris- $\mathrm{HCl}, \mathrm{pH} 8 \cdot 0)$ freeze/ thaw procedure, followed by $60{ }^{\circ} \mathrm{C}$ heating for $10 \mathrm{~min}$ to inactivate endogenous deacetylase activity. After centrifugation (20 $000 \boldsymbol{g}$ for $2 \mathrm{~min}$ ), supernatants were transferred to fresh tubes and processed for CAT enzyme activity. Each reaction was initiated by adding the cofactor $n$-butyryl Coenzyme A to tubes containing cell extracts and radiolabelled $\left[{ }^{3} \mathrm{H}\right]$ chloramphenicol. The CAT reaction was stopped and the butyrylated forms of $\left[{ }^{3} \mathrm{H}\right]$ chloramphenicol were separated by three consecutive extractions with mixed xylene. The extracts were transferred to vials for liquid scintillation counting. The c.p.m. measured in each sample represents the butyrylated fraction of the $\left[{ }^{3} \mathrm{H}\right]$ chloramphenicol and is directly proportional to CAT gene expression (as determined by a standard curve).

\section{Immunostaining procedures and fluorescence quantitation}

Cells were fixed/permeabilised with methanol at $-20{ }^{\circ} \mathrm{C}$ for $10 \mathrm{~min}$, followed by $30 \mathrm{~min}$ incubation with $5 \%$ bovine serum albumin (BSA) to block non-specific antibody binding. Cells were then incubated with the rabbit polyclonal antibody 57 (GR57) against the human GR (Affinity BioReagents, Golden, CO, USA) (Cidlowski et al. 1990), at a concentration of $5 \mu \mathrm{g} / \mathrm{ml}$ in $2 \%$ normal donkey serum (NDS) in PBS for $30 \mathrm{~min}$ at room temperature, followed by overnight incubation at $4{ }^{\circ} \mathrm{C}$. The following day, cells were incubated with biotinconjugated donkey anti-rabbit antibody (Jackson Immunoresearch Laboratories, West Grove, PA, USA), at a concentration of $10 \mu \mathrm{g} / \mathrm{ml}$ in NDS for $1 \mathrm{~h}$, followed by incubation with the fluorescein isothiocyanate (FITC)conjugated streptavidin (Jackson Immunoresearch Laboratories) at a concentration of $9 \mu \mathrm{g} / \mathrm{ml}$ in PBS for $1 \mathrm{~h}$ (in darkness). Incubations and washes were performed at room temperature unless otherwise specified. Two washes with PBS were performed between all steps. Cells were mounted with a glass coverslip using the Slowfade-Light Antifade reagent in glycerol buffer (Molecular Probes, Eugene, OR, USA). Microscopic examination was performed using a Nikon Microphot-SA microscope with a
Nikon PlanApo 20/0.75 objective. The u.v. source was a Nikon Mercury Lamp HB-10101 AF.

The procedure for the quantitative analysis of fluorescence in the cytoplasm and in the nucleus was developed in consultation with Dr David E Wolf (Cell Biology Group, Worcester Foundation for Biomedical Research, Worcester, MA, USA) and had been described previously (Pariante et al. 1997, 1999). Briefly, microscopic fields were captured under both light and fluorescence illuminations and transformed into digital images to be shown on a computer screen. Sampling was performed on two to four different areas of each well. The microscope and the camera settings were maintained constant between all the experimental conditions, and no adjustment of the grey scale was performed in the images. A region of interest (ROI) was selected in the cytoplasm and in the nucleus of each cell of the section. The intensity value of each pixel within the ROI ranged between 0 and 255 and was proportional to the number of fluorescent photons emitted from the corresponding point in the specimen. After subtraction of the background (no cells), the mean intensity value of the ROI was calculated. This value represented a measure of the florescence detected from each ROI and could be used to make comparisons between the same cell compartments under different conditions. Several steps were included, to ensure an objective and accurate series of measurements. Firstly, the ROI was initially outlined 'blind' to the fluorescent signal (and to the treatment condition) using light microscopy images, and afterwards the selections were superimposed onto the corresponding fluorescent image and the fluorescence intensity in the region was quantified. Secondly, the ROI was defined using the oval tool of the image software and its width was kept constant. Thirdly, the entire cell and the nucleus were manually demarcated and the resulting areas (number of pixels) were calculated to control for possible changes in the shape of the cells.

Preparation of L929 cells for immunoprecipitation/western blotting, cellular fractionation and immunoprecipitation of GR protein

After incubation with drugs in $175 \mathrm{~cm}^{2}$ flasks, cells were washed and scraped in cold HBSS, transferred to $50 \mathrm{ml}$ tubes, pelleted at $700 \mathrm{~g}$ for $10 \mathrm{~min}$, resuspended in HBSS for three to five consecutive washes and then homogenised. Cellular fractionation and immunoprecipitation of GR were performed according to a procedure that generates soluble cytosolic and nuclear fractions (modified from Sanchez et al. 1994). Cells were resuspended in hypotonic buffer (10 mM HEPES, 5 mM EDTA, $20 \mathrm{mM}$ sodium molybdate, $\mathrm{pH} 7 \cdot 4$, with a cocktail of protease inhibitors including aprotinin $(0 \cdot 01 \mathrm{mg} / \mathrm{ml})$, leupeptin $(0.01 \mathrm{mg} / \mathrm{ml})$, soybean trypsin inhibitor $(0.01 \mathrm{mg} / \mathrm{ml})$, 
and phenylmethylsulphonyl fluoride $(0.16 \mathrm{mg} / \mathrm{ml}))$ followed by Dounce homogenisation. After centrifugation at $1000 \mathrm{~g}$ for $5 \mathrm{~min}$, the cytosolic (supernatant) and nuclear fractions (pellet) were saved. The cytosolic fraction was centrifuged again at $20000 \mathrm{~g}$ for $10 \mathrm{~min}$, and the resulting supernatant was collected for salt extraction. The nuclear fraction was resuspended in hypotonic buffer, centrifuged at $900 \mathrm{~g}$ for $5 \mathrm{~min}$, and this pellet was resuspended again in hypotonic buffer and collected for salt extraction. Each fraction was then solubilised using $1 \mathrm{~h}$ of salt extraction ( $5 \mathrm{mM}$ EDTA, $20 \mathrm{mM}$ sodium molybdate, $1 \mathrm{M} \mathrm{NaCl}$ ). The nuclear fraction was centrifuged again $(20000 \mathrm{~g}$, $10 \mathrm{~min})$, and the supernatant was collected. Finally, the rabbit polyclonal antibody 59 (GR59) against the human GR (Affinity Bioreagents) (Cidlowski et al. 1990) was added to the samples at a final concentration of $2 \mu \mathrm{g} / \mathrm{ml}$, for an overnight incubation. The above procedures were all carried out at $4{ }^{\circ} \mathrm{C}$. The GR-antibody immunocomplexes were isolated by the addition of protein A-Sepharose, followed by two centrifugation/wash steps, and extraction in sodium dodecyl sulphate (SDS) sample buffer by heating at $95^{\circ} \mathrm{C}$.

\section{Gel electrophoresis and quantitative western blotting}

Samples were resolved by electrophoresis in $4-7 \%$ polyacrylamide-SDS gel as described by Laemmli (1970). After transfer of the protein content to an Immobilon-P membrane (Millipore, Bedford, MA, USA) the relative amounts of GR protein in the cytosolic and nuclear fractions were determined using western blot analysis (modified from Sanchez et al. 1994). The membrane was incubated with $0 \cdot 2 \%$ BSA in Tris-buffered saline with $0 \cdot 1 \% \mathrm{v} / \mathrm{v}$ Tween-20 (BSA-TBST) for 5 min (blocking step), followed by incubation overnight with the rabbit polyclonal antibody 57 (GR57) against the human GR (Affinity BioReagents), $0.5 \mu \mathrm{g} / \mathrm{ml}$ in BSA-TBST. The GR57 antibody recognises a different epitope on the GR (aa 346-367) than the GR59 antibody used for immunoprecipitation (aa 245-259). After the application of purified horseradish peroxidase-labelled goat anti-rabbit IgG second antibody (Kirkegaard \& Perry Laboratories, Gaithersburg, MD, USA), 1:25000 in 10\% v/v foetal bovine serum in TBST, the GR protein was visualised using the Enhanced Chemiluminescence detection system (Amersham, Amersham, Bucks, UK).

As previously described (Pariante et al. 1997), film images of the blots were scanned and then analysed using a specific NIH-Image software algorithm that subtracts the background signal and integrates the width and the optical density of each band as an area under the curve (AUC) graphic. The corresponding value (dimension of the AUC) allowed a relative quantitation of the amount of GR protein in the cytosolic and nuclear fractions under the different conditions.
Competition assays and GR binding with radiolabelled [3H]Dex

GR binding was determined using a previously described in vitro cytosolic exchange assay (Miller et al. 1992, 1997, Pariante et al. 1997, 1999). Cells were fractionated using a freeze/thaw procedure in a volume of $0.7 \mathrm{ml}$ binding buffer $(10 \mathrm{mM}$ Tris, $1 \mathrm{mM}$ EDTA, $20 \mathrm{mM}$ molybdic acid, $5 \mathrm{mM}$ dithiothreitol, and 10\% glycerol in doubledistilled water, $\mathrm{pH} 7 \cdot 4$ at $4{ }^{\circ} \mathrm{C}$ ), yielding an approximate final protein concentration of $0.5-1.5 \mathrm{mg} / \mathrm{ml}$ cytosol. After centrifugation at $105000 \mathrm{~g}$ for $60 \mathrm{~min}$ at $4{ }^{\circ} \mathrm{C}$, the supernatant-cytosol was then added to incubation solutions containing radiolabelled $\left[{ }^{3} \mathrm{H}\right] \mathrm{Dex}$ with or without unlabelled competitor. Bound radiolabelled steroid was separated from unbound steroid by filtration through minicolumns containing $1.25 \mathrm{ml}$ LH-20 Sephadex (Pharmacia, Piscataway, NJ, USA). Scintillation fluor (Ultima Gold, Packard, Meridien, CT, USA) was added to eluate containing the bound fraction of steroid, and tritium $\left({ }^{3} \mathrm{H}\right)$ radioactivity was determined in a Wallac LKB 1209 liquid scintillation counter (LKB, Uppsala, Sweden).

Several steps were included to reduce the amount of residual drug present in the incubation mixture. These included three to five washes in HBSS after drug treatment, and a further 50-fold dilution of cytosol before incubation with the radioligand. Incubations with $\left[{ }^{3} \mathrm{H}\right]$ Dex were carried out (at 14 -fold above its $K_{\mathrm{d}}$ ) at $4{ }^{\circ} \mathrm{C}$ for $18-22 \mathrm{~h}$, to allow full exchange of the radiolabelled Dex with any residual competitor. Specific binding was expressed as femtomoles per milligram of cytosolic protein. Protein content for all samples was determined by the method of Bradford (1976) with use of BSA as a standard.

For competition assays, L929 cells were fractionated and lysates were centrifuged. The supernatant-cytosol was then added to incubation solutions containing radiolabelled $\left[{ }^{3} \mathrm{H}\right]$ Dex with $\log$ molar concentrations of RU40555 or unlabelled Dex $(-6$ to -10$) . K_{\mathrm{i}}$ values were calculated using the equation of Cheng \& Prusoff (1973).

\section{Digital processing system}

A digital processing system including a computer station, image analysis software and two devices for image acquisition (a camera and a scanner) was used to acquire, store and process the microscopic and the western blot images, and to perform the quantitative analyses.

The Macintosh Quadra 950 computer and the imaging software package NIH-Image were selected. The latter is a public domain software (written by Wayne S Rasband at the US National Institute of Health) available from the Internet by anonymous FTP from zippy.nimh.nih.gov. Image acquisition was performed using a charge-coupled device camera CCD 72 (MTI) and the scanner Relisys 


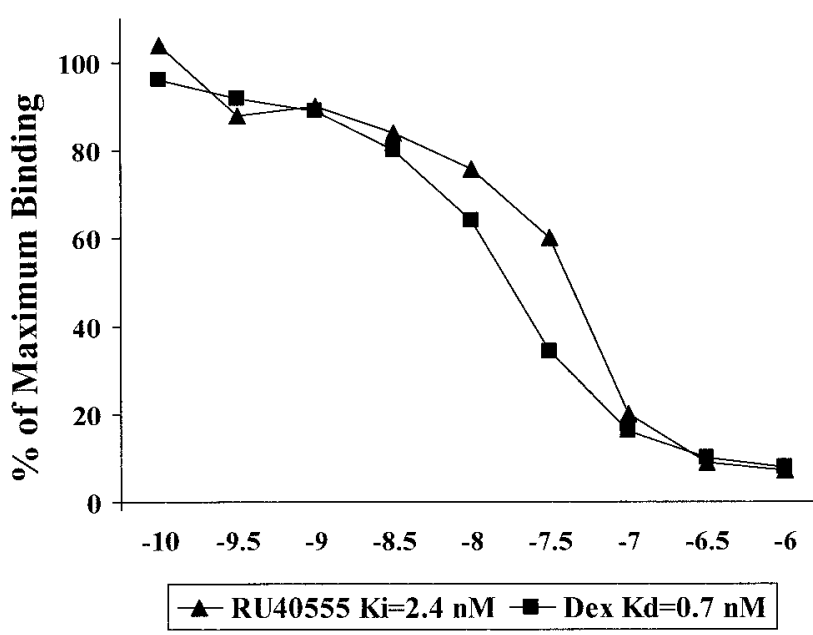

Figure 1 Competition of RU40555 and unlabelled Dex for binding of $\left[{ }^{3} \mathrm{H}\right]$ Dex. $L 929$ cells were fractionated and lysates were centrifuged. The supernatant-cytosol was then added to incubation solutions containing radiolabelled $\left[{ }^{3} \mathrm{H}\right]$ Dex with log molar concentrations of RU40555 or unlabelled Dex ( -6 to

-10). Data are expressed as percentage of maximum binding. One-site competition binding regression was obtained using the GraphPad Prism graphic software program and the $K_{\mathrm{i}}$ value for RU40555 (2.4 nM) was calculated using the equation of Cheng \& Prusoff (1973).

4830T. Conversion of the analog video signal into digital values was performed using a DT2255 QuickCapture frame grabber (Data Translation). The digital images were composed of 512X512 pixels and the value of the pixel (grey level) ranged between 0 and 255.

\section{Statistical analysis}

Data are presented as means \pm S.E.M. and were analysed using a one-way ANOVA or a Kruskal-Wallis test. When these tests revealed a significant main effect of treatment condition, the Student-Newman-Keuls post-hoc test (after ANOVA) or the Mann-Whitney test (after Kruskal-Wallis test) was used for between-group comparisons.

\section{Results}

RU40555 effectively competes for $\left.P^{3} H\right] D e x$ binding sites and shows high affinity for the GR

RU40555 and RU486 are structurally homologous, but the site-specific binding of RU40555 to the GR has not been reported. Therefore, competition binding assays were performed using $\left[{ }^{3} \mathrm{H}\right]$ Dex $(10 \mathrm{nM})$ with $\log$ molar concentrations of RU40555 or unlabelled Dex ( -6 to -10) (Fig. 1). RU40555 competed for the binding of labelled Dex with a $K_{\mathrm{i}}$ of $2 \cdot 4 \mathrm{nM}$, and Dex had a $K_{\mathrm{d}}$ of $0.7 \mathrm{nM}$. Previous studies have demonstrated that RU486 binds with a similar, high affinity to the murine GR $\left(K_{\mathrm{d}} / K_{\mathrm{i}}\right.$ in the range 0.7-3 nM (Bourgeois et al. 1984, Gagne et al. 1986, Rupprecht et al. 1993, Yu et al. 1995, Wagner et al. 1999)). Therefore, both GR antagonists have high, comparable affinity for GR.

We also used these results to plan the experiments investigating the effects of Dex, RU40555 and RU486 on GR function and GR subcellular localisation. To test the potency of RU40555 and RU486 to block GR-mediated gene transcription in the presence of Dex, and to induce maximum GR translocation with these three drugs, we used Dex $(10 \mu \mathrm{M})$, RU40555 $(40 \mu \mathrm{M})$ and RU486 $(40 \mu \mathrm{M})$. These concentrations are all approximately 15000 -fold the value of the $K_{\mathrm{d}} / K_{\mathrm{i}}$ of the drugs.

\section{RU40555 and RU486 equally block GR-mediated gene} expression and show weak agonistic activity after prolonged incubation

GR-mediated gene expression was examined in LMCAT cells. Expression of the CAT enzyme reporter gene in these cells is under hormonal control by virtue of several GREs residing upstream of the CAT gene (Sanchez et al. 1994).

LMCAT cells were treated for $1.5 \mathrm{~h}$ with Dex $(10 \mu \mathrm{M})$ alone, or in combination with RU486 $(40 \mu \mathrm{M})$ or RU40555 $(40 \mu \mathrm{M})$. Moreover, to evaluate if RU40555 and RU486 alone had any agonistic activity, LMCAT cells were treated with RU40555 $(40 \mu \mathrm{M})$ or RU486 $(40 \mu \mathrm{M})$ alone, for $1.5 \mathrm{~h}$ and for $24 \mathrm{~h}$. Values are expressed as percentage of the baseline CAT activity of vehicletreated cells. As shown in Fig. 2, and consistent with the findings of our previous studies (Pariante et al. 1997), Dex $(10 \mu \mathrm{M})$ for $1.5 \mathrm{~h}$ induced a $15-20$-fold increase in CAT gene expression (see Materials and Methods). This increase in CAT activity was fully inhibited by co-treatment with either RU486 or RU40555. Alone, RU40555 and RU486 showed a weak agonistic activity after $24 \mathrm{~h}$ of incubation $(+100 \%$ and $+176 \%$, respectively), but not after $1.5 \mathrm{~h}$.

Treatments with Dex $(10 \mu M), R U 40555(40 \mu M)$ and RU486 (40 $\mu M)$ induce GR translocation

We examined the subcellular localisation of GR after treatments with Dex $(10 \mu \mathrm{M})$, RU40555 $(40 \mu \mathrm{M})$ and RU486 $(40 \mu \mathrm{M})$, using a fluorescence/immunostaining procedure and western blot of the GR in the cytosolic and nuclear fractions. Both techniques were coupled to quantitative analyses able to define the relative amount of GR translocated in the various conditions.

In the first series of experiments, we evaluated the subcellular distribution of GR using a fluorescence/ immunostaining procedure. L929 cells stained for the GR after the various treatments are presented in Fig. 3a, together with results of the quantitative analysis (Fig. 3b). 


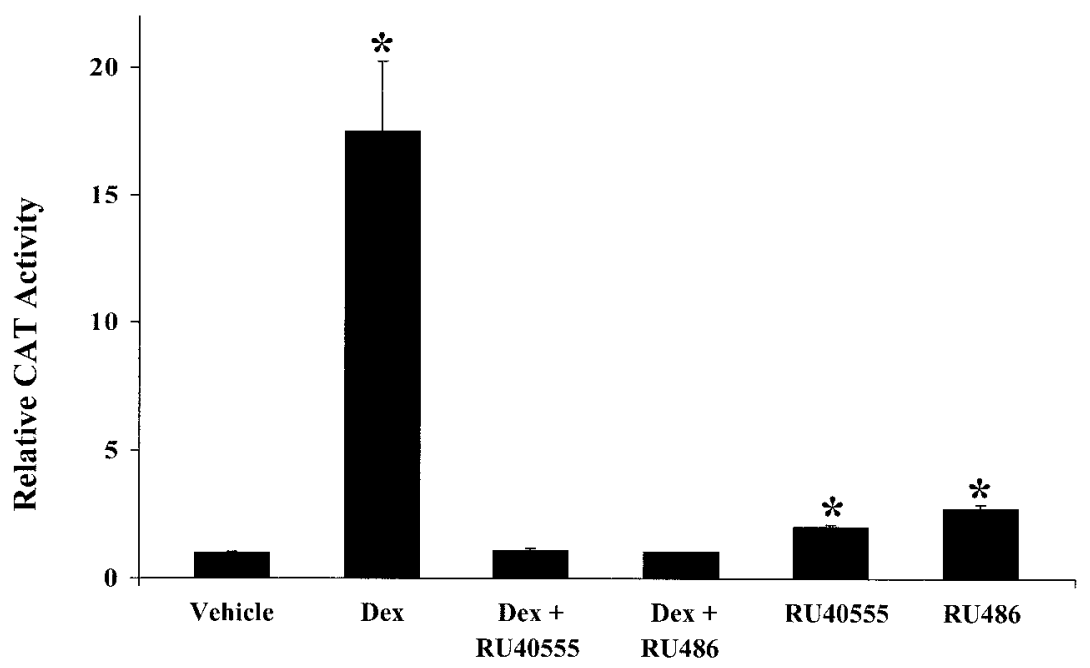

Figure 2 GR-mediated gene transcription after treatment with Dex, RU40555 and RU486, alone or in combination. LMCAT cells were treated for $1.5 \mathrm{~h}$ with vehicle alone, or Dex $(10 \mu \mathrm{M})$ alone or in combination with RU486 $(40 \mu \mathrm{M})$ or RU40555 $(40 \mu \mathrm{M})$, or with RU40555 $(40 \mu \mathrm{M})$ or RU486 $(40 \mu \mathrm{M})$ alone for $24 \mathrm{~h}$. Cells were then fractionated and lysates were analysed for relative CAT enzyme activity (fold induction relative to vehicletreated cells). The results are shown as the mean \pm S.E.M. of three independent experiments. *Significant difference $(P<0 \cdot 05)$ compared with vehicle using Student-Newman-Keuls post-hoc test after a significant ANOVA analysis.

GR signal was always present both in the cytoplasm and the nucleus of the cells. After treatment with vehicle (A), the pattern of staining was heterogeneous among cells, with a diffuse staining in both the cytoplasm and nucleus. In the majority of cells, the fluorescent signal was more intense in the cytoplasm than in the nucleus, although a few cells with brighter nuclei were present. Nucleoli were never stained. After treatment for $1.5 \mathrm{~h}$ with Dex $(10 \mu \mathrm{M})$ (B), RU40555 $(40 \mu \mathrm{M})(\mathrm{C})$, or RU486 $(40 \mu \mathrm{M})(\mathrm{D})$, all cells presented an intense nuclear staining, with nuclear fluorescence more intense than cytoplasmic fluorescence. To control for the specificity of the immunostaining for GR, a series of experiments were conducted in which the primary antibody anti-GR (GR57) was either preabsorbed against the immunogen peptide (PEP-001, from Affinity BioReagents) or substituted with NDS, or the second antibody (anti-rabbit $\operatorname{IgG}$ ) was substituted with NDS; controls were always negative. Fixed but unstained cells showed only minimal autofluorescence. There were no relevant differences among the various treatment conditions in the morphology of the cells or in the area of the entire cell or nucleus.

In order to determine whether there were any quantitative differences between GR translocation induced by the various compounds, quantitative analysis of fluorescence was performed in blindly selected regions from the cytoplasm and nucleus using digital image analysis in 800 cells (Fig. 3b). Results are expressed as percentage of the signal in the vehicle-treated cells. The quantitative analysis confirmed that all treatments - Dex $(10 \mu \mathrm{M})$, RU40555
$(40 \mu \mathrm{M})$ and RU486 $(40 \mu \mathrm{M})$ - reduced the GRassociated fluorescence in the cytoplasm (open bars) and increased the GR-associated fluorescence in the nucleus (solid bars) compared with vehicle-treated cells. All treatments induced an $\sim 30 \%$ decrease in the GR fluorescent signal in the cytoplasm. Dex $(10 \mu \mathrm{M})$ caused the greatest increase in the signal in the nucleus $(\sim 90 \%)$, whereas RU40555 $(40 \mu \mathrm{M})$ and RU486 $(40 \mu \mathrm{M})$ induced $\sim 25-$ $45 \%$ increase in the signal in the nucleus.

We also evaluated GR by immunoprecipitation/ western blot in the cytoplasmic and nuclear fractions obtained by cell rupture. A representative western blot is presented in Fig. $4 a$, together with results of the densitometric quantitation of the GR bands from five independent experiments (Fig. 4b). The rabbit polyclonal antibody 57 (GR57) against the human GR (Affinity BioReagents) recognised a prominent band at $\sim 97 \mathrm{kDa}$, consistent with the results of similar experiments performed with the same antibody in rat brain (O'Donnell et al. 1995) or with different monoclonal antibodies (Beck et al. 1993, Sanchez et al. 1994). In cells treated only with vehicle (lanes 1,2), the majority of GR was found in the cytosolic fraction. In contrast, treatments with Dex $(10 \mu \mathrm{M})$ (lanes 3, 4), RU40555 $(40 \mu \mathrm{M})($ lanes 5, 6) or RU486 $(40 \mu \mathrm{M})$ (lanes $7,8)$ resulted in GR mostly localised in the nuclear fraction. Densitometric quantitation of the GR bands is expressed in Fig. $4 b$ as a percentage of the signal in the vehicle-treated cells. Consistent and more dramatic than the results using the quantitative fluorescence/ immunostaining procedures, the densitometric analysis of 
(a)
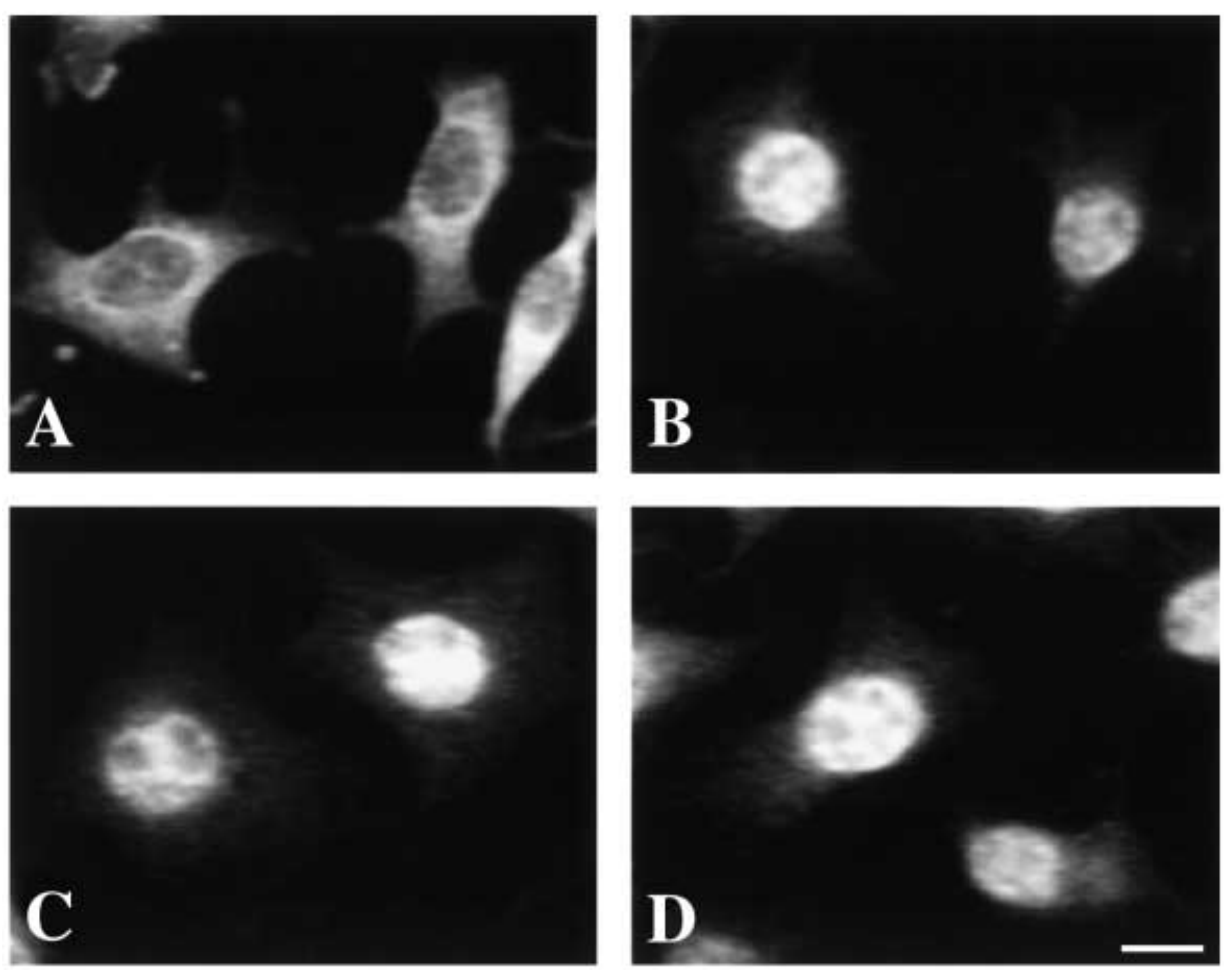

(b)

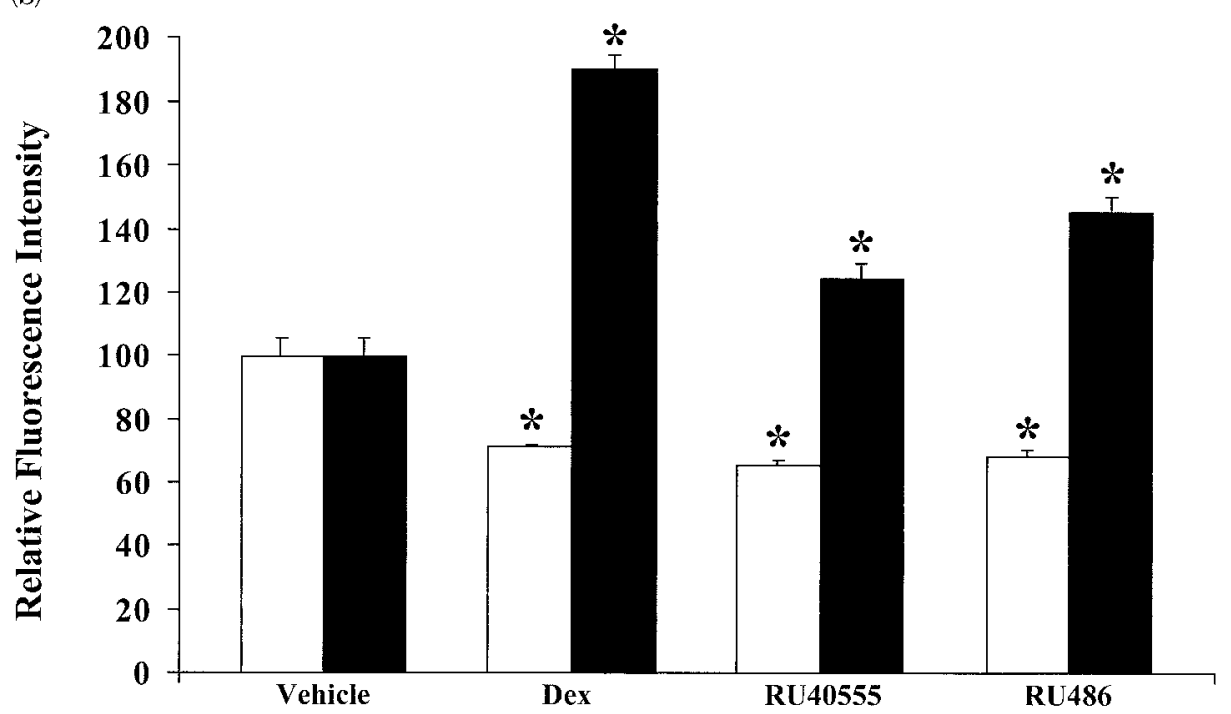

Figure 3 Nucleocytoplasmic traffic of GR after treatment with Dex $(10 \mu \mathrm{M})$, RU40555 $(40 \mu \mathrm{M})$ and RU486 $(40 \mu \mathrm{M})$. Immunostaining of GR and quantitation of fluorescence in the cytoplasm and in the nucleus. (a) L929 cells were treated for $1.5 \mathrm{~h}$ with vehicle (A), Dex $(10 \mu \mathrm{M})(\mathrm{B}), \mathrm{RU} 40555(40 \mu \mathrm{M})(\mathrm{C})$, or RU486 $(40 \mu \mathrm{M})(\mathrm{D})$. Cells were then fixed and GR was immunostained using the anti-GR polyclonal antibody GR57. Bar represents $10 \mu \mathrm{m}$. (b) Quantitative analysis of fluorescence (FITC) was performed in blindly selected regions from the cytoplasm (open bars) and nucleus (solid bars), using digital image analysis. Results are expressed as percentage of the signal in vehicle-treated cells and are presented as means \pm S.E.M. of approximately 800 cells from three to five independent experiments. ${ }^{*}$ Significant difference $(P<0 \cdot 05)$ compared with vehicle using Student-Newman-Keuls post-hoc test after a significant ANOVA analysis. 
(a)
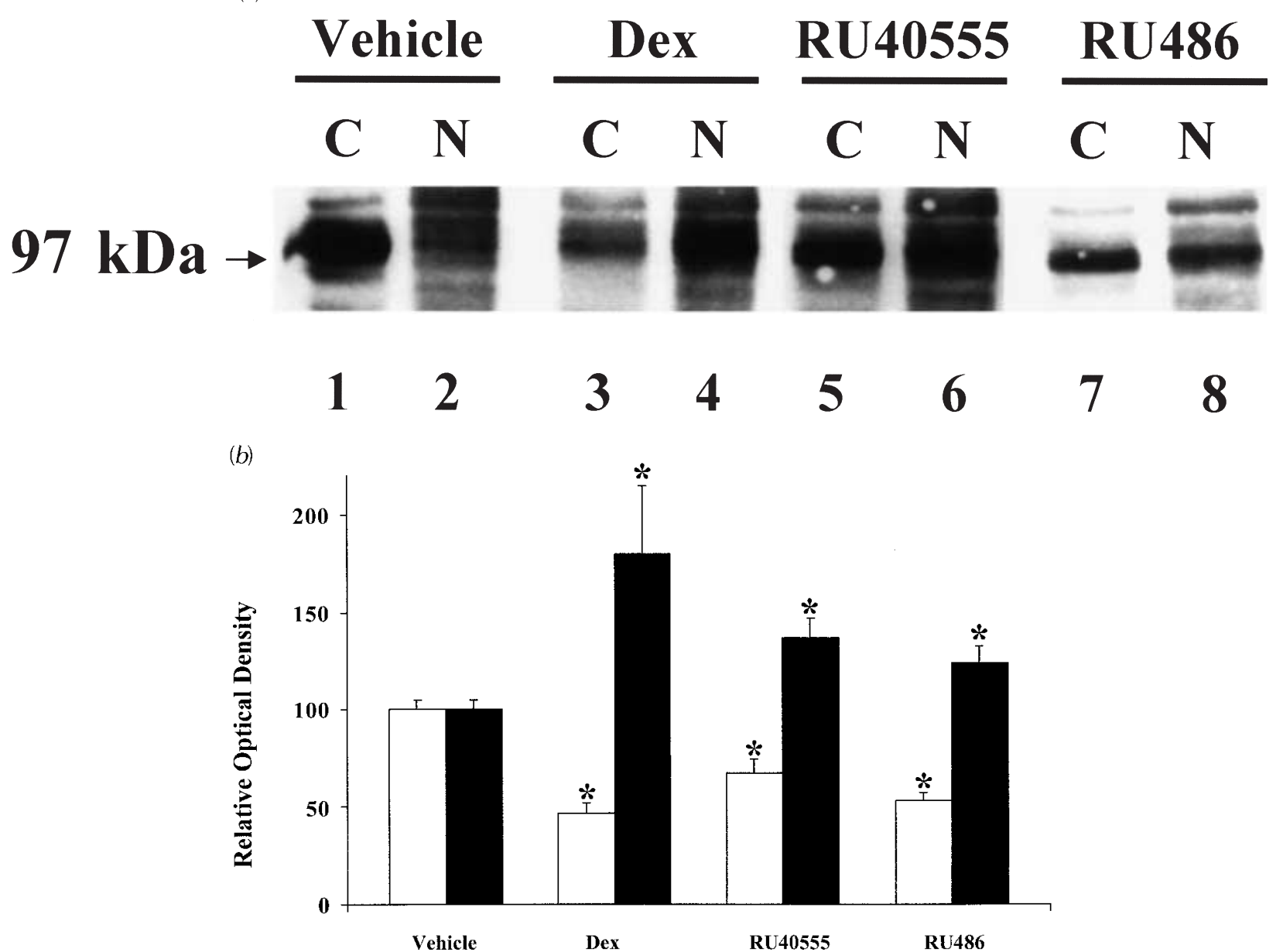

Figure 4 Nucleocytoplasmic traffic of GR after treatment with Dex $(10 \mu \mathrm{M})$, RU40555 $(40 \mu \mathrm{M})$ and RU486 (40 $\mu \mathrm{M})$. Western blot of the immunoprecipitated GR in the cytoplasmic and nuclear compartments and densitometric quantitation of GR bands. (a) L929 cells were treated for $1.5 \mathrm{~h}$ with vehicle (lanes 1, 2), Dex $(10 \mu \mathrm{M})$ (lanes 3, 4) RU40555 (40 $\mu \mathrm{M})$ (lanes 5, 6) or RU486 $(40 \mu \mathrm{M})($ lanes 7,8$)$. Cells were fractionated using a cell-rupturing procedure that generates soluble cytosolic and nuclear fractions. GR present in the fractions was purified with immunoprecipitation using the anti-GR polyclonal antibody, GR59, and analysed by western blot using the anti-GR polyclonal antibody, GR57, and a horseradish peroxidase-conjugated counterantibody. The GR57 recognised a prominent band at $\sim 97 \mathrm{kDa}$. (b) Quantitation of GR bands was based on densitometric analysis. Results are expressed as percentage of the GR signal in the cytosolic fraction (open bars) and the nuclear fraction (solid bars) of vehicle-treated cells, and are presented as means \pm S.E.M. of five independent experiments. *Statistically significant difference $(P<0 \cdot 02)$ compared with vehicle, using the Mann-Whitney test after a significant Kruskal-Wallis analysis.

GR bands in the western blot confirmed that all treatments reduced GR in the cytosolic fraction (open bars) and increased the signal in the nuclear fraction (solid bars). Dex $(10 \mu \mathrm{M})$ alone caused the greater decrease in the cytoplasmic signal $(\sim 55 \%)$ and the greatest increase in nuclear signal ( 80\%), whereas RU40555 $(40 \mu \mathrm{M})$ or RU486 $(40 \mu \mathrm{M})$ induced $\sim 35-45 \%$ decreases in the cytoplasmic signal and $\sim 25-40 \%$ increase in nuclear signal.

Effect of a steroid transporter inhibitor on the translocation of GR induced by 1-10 nM RU40555, RU486 or Dex

Previous studies have shown that Dex is a substrate for membrane steroid transporters such as the MDR p-glycoprotein (Ueda et al. 1992) and the L929 steroid transporter (Medh et al. 1998), whereas RU486 is not transported by the MDR p-glycoprotein (Gruol \& Bourgeois 1994). In L929 cells, the effects of the steroid transporter on intracellular concentrations of Dex are particularly evident at concentrations of $1-10 \mathrm{nM}$ and disappear at concentrations greater than $0 \cdot 1 \mu \mathrm{M}$ (Medh et al. 1998), because high concentrations of Dex could overwhelm the capacity of the transporter. Therefore, we hypothesised that Dex at concentrations of 1-10 nM would induce less GR translocation in L929 cells, compared with RU486 and RU40555, because intracellular concentrations of Dex (but not of the GR antagonists) 


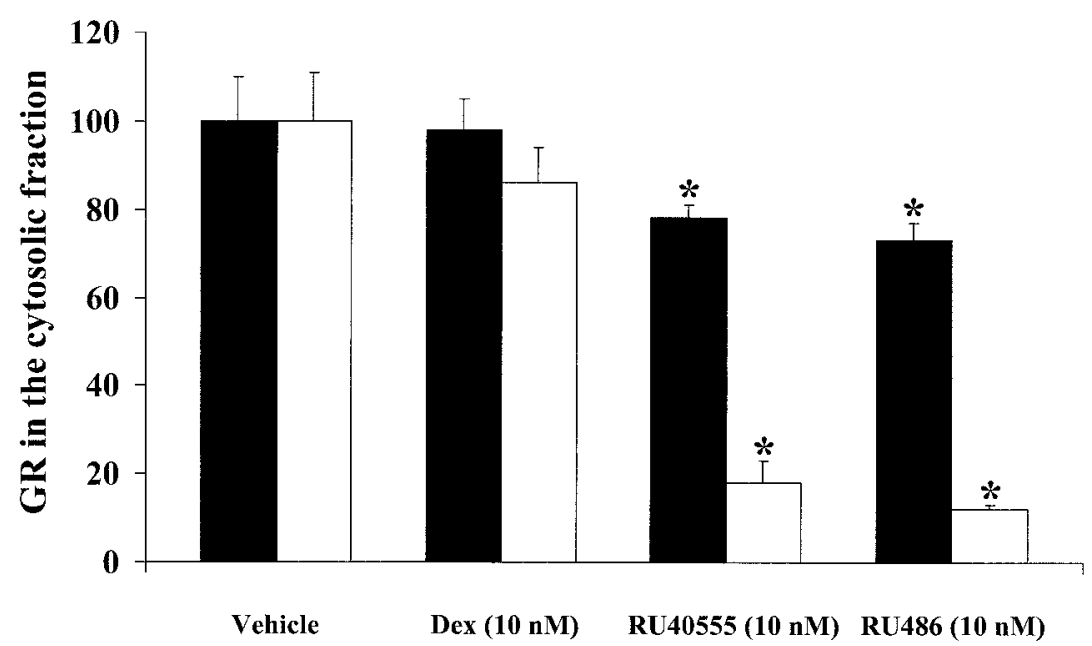

Figure 5 Nucleocytoplasmic traffic of GR after treatment with Dex (10 nM), RU40555 $(10 \mathrm{nM})$ and RU486 (10 nM). Quantitation of $\left[{ }^{3} \mathrm{H}\right]$ Dex binding and GR western blot in the cytosolic extracts. L929 cells were treated for $1.5 \mathrm{~h}$ with vehicle, Dex (10 nM), RU40555 $(10 \mathrm{nM})$, and RU486 (10 nM). For preparation of cytosolic extracts, cell lysates were centrifuged and the supernatant-cytosol was analysed by western blot using the anti-GR polyclonal antibody, GR57, or added to incubation solutions containing radiolabelled $\left.{ }^{3} \mathrm{H}\right]$ Dex for the exchange assay. Western blot is calculated as quantitation of GR bands by densitometric analysis, whereas GR binding is calculated as $\mathrm{fmol} / \mathrm{mg}$ cytosolic protein. Average GR binding in vehicle-treated cells was $1301 \pm 141 \mathrm{fmol} / \mathrm{mg}$ protein. Results are expressed as percentage of the GR western blot (solid bars) and GR binding (open bars) in the cytosolic fraction of vehicle-treated cells, and are presented as means \pm S.E.M. *Significant difference $(P<0 \cdot 05)$ compared with Dex $(10 \mathrm{nM})$, using Student-Newman-Keuls post-hoc test, after a significant ANOVA analysis.

would be decreased by the transporter. We examined the effects of $1.5 \mathrm{~h}$ treatment with Dex $(10 \mathrm{nM})$, RU40555 $(10 \mathrm{nM})$ and RU486 (10 nM) on cytosolic $\left[{ }^{3} \mathrm{H}\right]$ Dex binding and western blot of cytosolic GR. In fact, GR activation and translocation from the cytoplasm to the nucleus is associated with decreased $\left[{ }^{3} \mathrm{H}\right]$ Dex binding (Miller et al. 1992, 1997, Pariante et al. 1997) and decreased immunoreactive GR (Beck et al. 1993, Sanchez et al. 1994, O'Donnell et al. 1995, Sackey et al. 1996, Pariante et al. 1997) in the cytosolic fraction.

Results are presented in Fig. 5. Clearly, RU40555 $(10 \mathrm{nM})$ and RU486 (10 nM) induced more GR to translocate from the cytoplasm to the nucleus than did Dex $(10 \mathrm{nM})$. In fact, Dex $(10 \mathrm{nM})$ induced virtually no loss of immunoreactive GR in the cytosolic fraction (solid bars) and an $\sim 15 \%$ loss in the $\left[{ }^{3} \mathrm{H}\right] \mathrm{Dex}$ binding (open bars), whereas RU40555 (10 nM) and RU486 (10 nM) induced $\sim 25 \%$ loss of immunoreactive GR in the cytosolic fraction (solid bars) and a $\sim 80-85 \%$ loss in the $\left.{ }^{3} \mathrm{H}\right]$ Dex binding (open bars). Average GR binding in vehicle-treated cells was $1301 \pm 141 \mathrm{fmol} / \mathrm{mg}$ protein.

In a separate series of experiments, we also found that $1.5 \mathrm{~h}$ treatment with RU40555 (1 nM) and RU486 $(1 \mathrm{nM})$ induced more GR translocation than did Dex (1 $\mathrm{nM})$, using immunocytochemistry staining of GR and quantitative analysis of fluorescence in 350 cells. Dex $(1 \mathrm{nM})$ induced no loss in cytoplasmic fluorescence and $\sim 20 \%$ increase in the nuclear fluorescence, whereas RU40555 (1 nM) and RU486 (1 nM) induced 15-25\% loss in the cytoplasmic fluorescence and $35-50 \%$ increase in the nuclear fluorescence.

We then examined whether $18 \mathrm{~h}$ pretreatment with verapamil $(100 \mu \mathrm{M})$, a known inhibitor of the L929 cells steroid transporter (Medh et al. 1998), would increase the amount of GR translocating from the cytoplasm to the nucleus in the presence of Dex $(10 \mathrm{nM})$ by increasing Dex intracellular concentrations. As expected, pretreatment with verapamil increased GR translocation in the presence of Dex $(10 \mathrm{nM})$ to levels similar to those induced by RU40555 (10 nM) and RU486 (10 nM). In fact, Dex $(10 \mathrm{nM})$ plus verapamil induced $\sim 35 \%$ loss in the cytosolic immunoreactive GR (compared with no loss with Dex $(10 \mathrm{nM})$ alone) and $\sim 85 \%$ loss in $\left[{ }^{3} \mathrm{H}\right] \operatorname{Dex}$ cytosolic binding (compared with 15\% loss with Dex $(10 \mathrm{nM})$ alone). Pretreatment with verapamil had no effect on GR translocation in the presence of RU40555 $(10 \mathrm{nM})(\sim 20 \%$ loss in the cytosolic immunoreactive GR and $\sim 90 \%$ loss in cytosolic binding) or RU486 (10 nM) $(\sim 30 \%$ loss in the cytosolic immunoreactive GR and $\sim 85 \%$ loss in cytosolic binding). 


\section{Discussion}

A panel of quantitative assays were used to investigate GR-mediated gene transcription and GR nucleocytoplasmic traffic after treatment with the synthetic glucocorticoid hormone, Dex, and the GR antagonists, RU40555 and RU486. All experiments were performed in mouse L929 cells.

\section{Affinity of RU40555 for GR}

We found that RU40555 competed for the binding of Dex with a $K_{\mathrm{i}}$ of $2.4 \mathrm{nM}$, and Dex had a $K_{\mathrm{d}}$ of $0.7 \mathrm{nM}$. Previous studies have demonstrated that RU486 binds with a high affinity to the GR, with $K_{\mathrm{d}} / K_{\mathrm{i}}$ in the range 0.7-3 nM (Bourgeois et al. 1984, Gagne et al. 1986, Rupprecht et al. 1993, Yu et al. 1995, Wagner et al. 1999). Most previous studies have also shown that Dex has $K_{\mathrm{d}}$ values ranging from 0.5 to $2.5 \mathrm{nM}$ (Spencer et al. 1990, 1991, Miller et al. 1992, 1997, Rupprecht et al. 1993, Yu et al. 1995), although $K_{\mathrm{d}}$ values in the 5-10 nM range have been described (Lan et al. 1982, Wagner et al. 1999). In the few studies that have compared the affinity of Dex and of RU486 for the GR under the same experimental conditions, Dex has shown both a slightly greater affinity (Rupprecht et al. 1993) and a slightly lesser affinity (Bourgeois et al. 1984, Yu et al. 1995, Wagner et al. 1999). Therefore, on the basis of information in the available literature and our data, Dex, RU486 and RU40555 seem to have comparable, high affinity for GR.

\section{Effects on GR translocation and GR-mediated gene transcription}

Consistently throughout the different techniques we demonstrated that GR was localised preferentially in the cytoplasm of untreated cells and that treatment with Dex, RU40555 and RU486 decreased GR content in the cytoplasm and increased GR content in the nucleus. RU486-induced GR translocation has been described previously (Qi et al. 1990, Rupprecht et al. 1993, Jewell et al. 1995, Htun et al. 1996, Sackey et al. 1996), but this is the first report, to our knowledge, that describes a similar phenomenon occurring with RU40555.

Interestingly, GR antagonists, like RU486 and RU40555, induce significant GR nuclear translocation but exert minimal agonistic activity in GR functional assays (such as GR-mediated gene transcription). In our report, RU40555 and RU486 alone elicited weak agonistic activity with prolonged incubation. Therefore, GR antagonists seem unable to induce the correct conformational change in the receptor and to activate fully either GR-mediated chromatin remodelling or transcription factor loading, or both (Nordeen et al. 1995, Fryer et al. 2000). Indeed, differences have been described between RU486-induced GR activation and agonistsinduced GR activation: 1) RU486 stabilises the interaction between GR and hsps (Distelhorst \& Howard 1990, Beck et al. 1993); 2) the RU486-GR complex interacts with DNA with a much lower affinity than that of the Dex-GR complex (Bourgeois et al. 1984, Yu et al. 1995, Wagner et al. 1999); and 3) the RU486-GR complex is different from the agonists-GR complex in terms of recycling to the cytoplasm (Qi et al. 1990, Sackey et al. 1996). However, binding of the RU486-GR complex to DNA allows for some agonistic activity to take place and explains why RU486 can induce full GR agonistic activity when recruitment of other transcriptional coactivators is facilitated by the enhancement of intracellular signal pathways such as the protein kinase A pathway (Gruol \& Altschmied 1993, Nordeen et al. 1995, Fryer et al. 2000), or in some specific cell lines (Fryer et al. 2000).

Effects of verapamil on GR translocation in the presence of Dex, RU40555 and RU486

Various authors have reported that L929 cells express a membrane steroid transporter that actively decreases intracellular concentration of Dex and that it is blocked by verapamil and FK506 (Kralli \& Yamamoto 1996, Marsaud et al. 1998, Medh et al. 1998). Although the substrate profile of this transporter is very similar to that of the MDR p-glycoprotein (Ueda et al. 1992, Krishna \& Mayer 2000), two independent studies have failed to detect MDR p-glycoprotein immunoreactivity using western blot of L929 cells (Kralli \& Yamamoto 1996, Marsaud et al. 1998). Moreover, at least one functional difference seems to exist between the L929 steroid transporter and the MDR p-glycoprotein, namely that the MDR p-glycoprotein - but not the L929 transporter - is inhibited by RU486 (Gruol \& Bourgeois 1994, Marsaud et al. 1998).

Our study confirms and extends these findings, by demonstrating that Dex, but not RU40555 and RU486, is actively expelled by the L929 steroid transporter, and that this effect is relevant for GR translocation, especially at lower concentrations of Dex. In fact, we found that: 1) at low concentrations (1-10 nM), Dex induced less GR translocation compared with RU40555 and RU486; 2) treatment with verapamil together with Dex $(10 \mathrm{nM})$ increased GR translocation to levels similar to those induced by RU40555 (10 nM) and RU486 (10 nM); and 3) verapamil had virtually no effect of GR translocation in the presence of RU40555 and RU486.

\section{Dissociation between immunoreactive GR and $\left.{ }^{3} H\right] D e x$ binding sites in the cytoplasm}

In our study we evaluated GR binding coupled with western blot of the same cytosolic homogenates. After 
blocking the steroid transporter with verapamil, all treatments - Dex (10 nM), RU40555 (10 nM) and RU486 $(10 \mathrm{nM})$ - induced similar amounts of GR loss in the cytoplasm and an evident discrepancy between the loss in $\left[{ }^{3} \mathrm{H}\right]$ Dex binding sites $(\sim 80-90 \%)$ and the loss in immunoreactive GR $(\sim 20-35 \%)$. These findings are remarkably consistent with those of an in vivo study by O'Donnell et al. (1995), which similarly used western blot and binding of the GR in the same cytosolic extracts obtained from rat brain tissue. In that study, adrenalectomised animals given replacement corticosterone pellets showed decreases in both immunoreactive GR and GR binding, although the magnitude of change in the binding was greater than that measured by western blot.

Immunoreactive GR in the cytoplasm that cannot rebind ligand may represent receptor that has recently dissociated from DNA and recycled to the cytoplasm, as it is known that this subpopulation of receptor is unable to rebind hormone immediately, probably because the GR has not yet reconstituted the complex with the hsps (Scherrer et al. 1990). Alternatively, some nuclear GR (that would also be unable to rebind steroids, for the same reason mentioned above) could have leaked to the cytosolic fraction during cell preparation. Under these experimental conditions, we found no differences between Dex-activated GR and antagonists-activated GR. Our results seem to confirm the findings of Sackey et al. (1996), showing that GR that has been previously translocated by RU486 does appear eventually to reassume a steroid-responsive form.

In conclusion, we found no differences between RU486 and RU40555 in the effects on GR and therefore both drugs could be used as potent tools to investigate GR function, GR modulation by ligands, and ligandindependent regulation of the GR (Pariante \& Miller 2001).

\section{Acknowledgement}

C M P is supported by a UK Medical Research Council Clinical Training Fellowship.

\section{References}

Beck CA, Estes PA, Bona BJ, Muro-Cacho CA, Nordeen SK \& Edwards DP 1993 The steroid antagonist RU486 exerts different effects on the glucocorticoid and progesterone receptors. Endocrinology 133 728-740.

Bourgeois S, Pfahl M \& Baulieu E-E 1984 DNA binding properties of glucocorticosteroid receptors bound to the steroid antagonist RU-486. EMBO Journal 3 751-755.

Bradford MM 1976 A rapid and sensitive method for the quantitation of microgram quantities of protein utilizing the principle of protein-dye binding. Analytical Biochemistry 72 248-254.
Cheng YC \& Prusoff WH 1973 Relationship between the inhibition constant $\left(k_{\mathrm{i}}\right)$ and the concentration of inhibitor which causes 50 per cent inhibition $\left(\mathrm{IC}_{50}\right)$ of an enzymatic reaction. Biochemical Pharmacology 22 3099-3108.

Cidlowski JA, Bellingham DL, Powell-Oliver FE, Lubahn DB \& Sar M 1990 Novel antipeptide antibodies to the human glucocorticoid receptor: recognition of multiple receptor forms in vitro and distinct localisation of cytoplasmic and nuclear receptors. Molecular Endocrinology 4 1427-1437.

Czar MJ, Lyons RH, Welsh MJ, Renoir J-M \& Pratt WB 1995 Evidence that the FK506-binding immunophilin heat shock protein 56 is required for trafficking of the glucocorticoid receptor from the cytoplasm to the nucleus. Molecular Endocrinology 9 1549-1560.

Distelhorst CW \& Howard KJ 1990 Evidence from pulse-chase labeling studies that the antiglucocorticoid hormone RU486 stabilizes the nonactivated form of the glucocorticoid receptor in mouse lymphoma cells. Journal of Steroid Biochemistry 36 25-31.

Fryer CJ, Kinyamu HK, Rogatsky I, Garabedian MJ \& Archer TK 2000 Selective activation of the glucocorticoid receptor by steroid antagonists in human breast cancer and osteosarcoma cells. Journal of Biological Chemistry 275 17771-17777.

Gagne D, Pons M \& Crastes de Paulet A 1986 Analysis of the relation between receptor binding affinity and antagonist efficacy of antiglucocorticoids. Journal of Steroid Biochemistry 25 315-322.

Gruol DJ \& Altschmied J 1993 Synergistic induction of apoptosis with glucocorticoids and $3^{\prime}, 5^{\prime}$-cyclic adenosine monophosphate reveals agonistic activity by RU486. Molecular Endocrinology 7 104-113.

Gruol DJ \& Bourgeois S 1994 Expression of the mdr P-glycoprotein gene: a mechanism of escape from glucocorticoid-induced apoptosis. Biochemistry and Cell Biology 72 561-571.

Htun H, Barsony J, Renyi I, Gould DL \& Hager GL 1996 Visualization of glucocorticoid receptor translocation and intranuclear organization in living cells with a green fluorescent protein chimera. PNAS 93 4845-4850.

Ing NH \& O’Malley B 1995 The steroid hormone receptor superfamily: molecular mechanisms of action. In Molecular Endocrinology: Basic Concepts and Clinical Correlations, pp 195-215. Ed. BD Weintraub. New York: Raven Press, Ltd

Jewell CM, Webster JC, Burnstein KL, Sar M, Bodwell JE \& Cidlowski JA 1995 Immunocytochemical analysis of hormone mediated nuclear translocation of wild type and mutant glucocorticoid receptors. Journal of Steroid Biochemistry and Molecular Biology 55 135-146.

Kim PJ, Cole MA, Kalman BA \& Spencer RL 1998 Evaluation of RU28318 and RU40555 as selective mineralocorticoid receptor and glucocorticoid receptor antagonists, respectively: receptor measures and functional studies. Journal of Steroid Biochemistry and Molecular Biology 67 213-222.

Kralli A \& Yamamoto KR 1996 An FK506-sensitive transporter selectively decreases intracellular levels and potency of steroid hormones. Journal of Biological Chemistry 271 17152-17156.

Krishna R \& Mayer LD 2000 Multidrug resistance (MDR) in cancer. Mechanisms, reversal using modulators of MDR and the role of MDR modulators in influencing the pharmacokinetics of anticancer drugs. European Journal of Pharmaceutical Sciences 11 265-283.

Laemmli UK 1970 Cleavage of structural proteins during the assembly of the head of bacteriophage T4. Nature 227 680-685.

Lan NC, Graham B, Bartter FC \& Baxter JD 1982 Binding of steroids to mineralocorticoid receptors: implications for in vivo occupancy by glucocorticoids. Journal of Clinical Endocrinology and Metabolism $\mathbf{5 4}$ 332-342.

Marsaud V, Mercier-Bodard C, Fortin D, Le Bihan S \& Renoir J-M 1998 Dexamethasone and triamcinolone acetonide accumulation in mouse fibroblasts is differently modulated by the immunosuppressants cyclosporin A, FK506, rapamycin and their analogues, as well as by other p-glycoprotein ligands. Journal of Steroid Biochemistry and Molecular Biology 66 11-25. 
Medh RD, Lay RH \& Schmidt TJ 1998 Agonist-specific modulation of glucocorticoid receptor-mediated transcription by immunosuppressants. Molecular and Cellular Endocrinology 138 $11-23$

Miller AH, Spencer RL, Pulera M, Kang S, McEwen BS \& Stein M 1992 Adrenal steroid receptor activation in rat brain and pituitary following dexamethasone: implications for the dexamethasone suppression test. Biological Psychiatry 32 850-869.

Miller AH, Spencer RL, Pearce BD, Pisell TL, Tanapat P, Leung JJ, Dhabhar FS, McEwen BS \& Biron CA 1997 Effects of viral infection on corticosterone secretion and glucocorticoid receptor binding in immune tissues. Psychoneuroendocrinology 22 455-474.

Nordeen SK, Bona BJ, Beck CA, Edwards DP, Borror KC \& DeFranco DB 1995 The two faces of a steroid antagonist: when an antagonist isn't. Steroids $6097-104$.

O’Donnell D, Francis D, Weaver S \& Meaney MJ 1995 Effects of adrenalectomy and corticosterone replacement on glucocorticoid receptor levels in rat brain tissue: a comparison between western blotting and receptor binding assays. Brain Research 687 133-142.

Pariante CM \& Miller AH 2001 Glucocorticoid receptors in major depression: relevance to pathophysiology and treatment. Biological Psychiatry 49 391-404.

Pariante CM, Pearce BD, Pisell TL, Owens MJ \& Miller AH 1997 Steroid-independent translocation of the glucocorticoid receptor by the antidepressant desipramine. Molecular Pharmacology $\mathbf{5 2}$ 571-581.

Pariante CM, Pearce BD, Pisell TL, Sanchez CI, Po C, Su C \& Miller AH 1999 The proinflammatory cytokine, interleukin-1 alpha, reduces glucocorticoid receptor translocation and function. Endocrinology 140 4359-4366.

Picard D \& Yamamoto KR 1987 Two signals mediate hormonedependent nuclear localization of the glucocorticoid receptor. EMBO Journal 6 3333-3340.

Pratt WB 1993 The role of heat shock proteins in regulating the function, folding, and trafficking of the glucocorticoid receptor. Journal of Biological Chemistry 268 21455-21458.

Qi M, Stasenko LJ \& DeFranco DB 1990 Recycling and desensitization of glucocorticoid receptors in v-mos transformed cells depend on the ability of nuclear receptors to modulate gene expression. Molecular Endocrinology 4 455-464.

Rupprecht R, Reul JMHM, van Steensel B, Spengler D, Soder M, Berning B, Holsboer F \& Damm K 1993 Pharmacological and functional characterization of human mineralocorticoid and glucocorticoid receptor ligands. European Journal of Pharmacology 247 $145-154$.
Sackey FNA, Hache RJG, Reich T, Kwast-Welfeld J \& Lefebvre YA 1996 Determinants of subcellular distribution of the glucocorticoid receptor. Molecular Endocrinology 10 1191-1205.

Sanchez ER, Hu J-L, Zhong S, Shen P, Greene MJ \& Housley PR 1994 Potentiation of glucocorticoid receptor-mediated gene expression by heat and chemical shock. Molecular Endocrinology 8 408-421.

Scherrer LC, Dalman FC, Massa E, Meshinchi S \& Pratt WB 1990 Structural and functional reconstitution of the glucocorticoid receptor-hsp90 complex. Journal of Biological Chemistry 265 21397-21400.

Schmidt TJ 1986 In vitro activation and DNA binding affinity of human lymphoid (CEM-C7) cytoplasmic receptors labelled with the antiglucocorticoid RU 38486. Journal of Steroid Biochemistry 24 853-863.

Spencer RL, Young EA, Choo PH \& McEwen BS 1990 Adrenal steroid type I and type II receptor binding: estimates of in vivo receptor number, occupancy, and activation with varying level of steroid. Brain Research 514 37-48.

Spencer RL, Miller AH, Stein M \& McEwen BS 1991 Corticosterone regulation of Type I and Type II adrenal steroid receptors in brain, pituitary, and immune tissue. Brain Research 549 236-246.

Spencer RL, Kim PJ, Kalman BA \& Cole MA 1998 Evidence for mineralocorticoid receptor facilitation of glucocorticoid receptordependent regulation of hypothalamic-pituitary-adrenal axis activity. Endocrinology 139 2718-2726.

Ueda K, Okamura N, Hirai M, Tanigawara Y, Saeki T, Kioka N, Komano T \& Hori R 1992 Human P-glycoprotein transports cortisol, aldosterone, and dexamethasone, but not progesterone. Journal of Biological Chemistry $26724248-24252$.

Wagner BL, Pollio G, Giangrande P, Webster JC, Breslin M, Mais DE, Cook CE, Vedeckis WV, Cidlowsky JA \& McDonnell DP 1999 The novel progesterone receptor antagonists RTI 3021-012 and RTI 3021-022 exhibit complex glucocorticoid receptor antagonist activities: implications for the development of dissociated antiprogestins. Endocrinology 140 1449-1458.

Yang J \& DeFranco DB 1996 Assessment of glucocorticoid receptorheat shock protein 90 interactions in vivo during nucleocytoplasmic trafficking. Molecular Endocrinology 10 3-13.

Yu C, Warriar N \& Govindan MV 1995 Cysteines 638 and 665 in the hormone binding domain of human glucocorticoid receptor define the specificity to glucocorticoids. Biochemistry $\mathbf{3 4}$ 14163-14173.

Received 9 December 2000

Accepted 22 December 2000 